Original Research Article

\title{
Knowledge, awareness and attitude towards rational use of medicines by community pharmacists in and around Coimbatore, India
}

\author{
Bhuvaneswari K.*, Jeyalakshmi D., Umamaheswari A.
}

Department of Pharmacology, PSG Institute of Medical Sciences and Research, Coimbatore, Tamil Nadu, India

Received: 27 July 2017 Accepted: 23 August 2017

*Correspondence to:

Dr. Bhuvaneswari K., Email: nandabhuvana@ gmail.com

Copyright: (C) the author(s), publisher and licensee Medip Academy. This is an openaccess article distributed under the terms of the Creative Commons Attribution NonCommercial License, which permits unrestricted noncommercial use, distribution, and reproduction in any medium, provided the original work is properly cited.

\begin{abstract}
Background: Achievement of goals of rational use of medicine (RUM) in the community is not possible without participation of community pharmacists. Pharmacists must know that they are the main tool to educate and spread information on rational use of medicine in the community. This background enabled this study to observe the knowledge, awareness and attitude of the community pharmacists towards the rational use of medicine. Aim and Objectives were to assess the knowledge and awareness among community pharmacists about rational drug use in and around Coimbatore.

Methods: It was a cross sectional observational study using a preformed questionnaire. Study participants were 215 Community Pharmacists (those are registered pharmacist running standalone pharmacy stores not affiliating to any institutions /hospitals/not a part of a large chain of stores) inside (115 Pharmacist) and around (100 Pharmacist) Coimbatore city. Questionnaire was given to them and results were analyzed and expressed in percentage at the end of the study.

Results: Comparing the awareness about RUM in the community pharmacists in and around Coimbatore was found with the results which was almost equal or less in terms of dispensing medicines without prescription, issuing medicines to outdated prescription, educating the public about ADR etc.

Conclusions: This study ensure the need of the community pharmacist participation for the development of a clear educational policy on promoting rational use of medicine involving all segments of health care system to ensure the community benefit and safety.
\end{abstract}

Keywords: Attitude, Awareness, Knowledge, Rational use of medicine, Pharmacist

\section{INTRODUCTION}

Rational uses of medicines (RUM) play an important role in clinical practice. The clinicians, pharmacists and the public should have an idea about rational use of medicine to prevent adverse drug reaction due to inappropriate use of medicine which will produce ill effects on health. The goal in rational use of medicine can be achieved only by participation of community pharmacists. The pharmacists form the bridge between the clinicians and patients. The reach of the pharmacists is extensive both in the community and hospital.
Community pharmacists are the first contact with public in terms of many common illnesses. Public have faith and confidence in community pharmacists because they were belonging to the same location and can be easily approached. Pharmacists in rural areas educate the patients about their illness and even guide them which clinician to consult for their illness. Its beyond medicine supply, community pharmacists have cordial relationship with the public. Community pharmacists form the key in unlocking the patient's ignorance towards rational use of medicine. In western world, it is documented that appropriate pharmacy practice by the pharmacist will lead us to reach the goal in rational use of medicine. 
World Health Organization has described RUM as "The meaning of rational use of medicine is that the patient gets appropriate medicine according to their clinical needs, in doses needed for their requirements for an adequate period and at a reasonable cost for both the patient and their community."

In a publication done by WHO only the rules and regulations of RUM was enumerated. Very few studies were conducted among the pharmacists. This study emphasises the vital role of pharmacists in concept of rational use of medicine and provide necessary education to them. Many pharmacists are aware of the consequences of irrational use of medicine. Pharmacists must know they are the main tool to educate patients about advantages of rational use of medicine. ${ }^{1}$

In another study, the participants were general practitioners and community pharmacists with patients diagnosed as upper respiratory infection where general practitioners were better than the pharmacists in concept of using antibiotics when compared to the pharmacists. ${ }^{2}$

One study was done with 756 community pharmacists. The pharmacists lacked public concern and were not keen about the RUM concept. The main reason for this was their diversities in education, influence by the management to get attached to drug policies and finally the most important was the financial needs. ${ }^{3}$

The patients must educate about various drugs, drug interactions and adverse effect due to irrational use of medicine. In another study $66 \%$ pharmacists explained ADR, $41 \%$ checking prescription validity, $87 \%$ maintains professional relationship, $12 \%$ consult other pharmacist and $81 \%$ explaining medicines effects. ${ }^{4}$

This was the first study to compare community pharmacists in urban and rural area of Coimbatore.

\section{Objectives}

1. To assess the knowledge and awareness among community pharmacists about rational drug use in and around Coimbatore.

2. To know the dispensing attitude of community pharmacist regarding rational drug use.

\section{METHODS}

The design of this study was 1 year, non-interventional, a Prospective cross sectional observational study was initiated using a preformed questionnaire.

\section{Inclusion criteria}

Community Pharmacists (those are registered pharmacist running standalone pharmacy stores not affiliating to any institutions /Hospitals/not a part of a large chain of stores).

\section{Exclusion criteria}

Pharmacists in nursing home, chains of pharmacy stores, multispecialty hospitals, and medical college hospitals, Government hospitals were excluded from this study.

After obtaining written informed consent, 215 Community Pharmacists (115 Pharmacist - inside Coimbatore city) and (100 Pharmacist outside Coimbatore city) were participated in this study. Study period was from October 2014 to February 2015. Questionnaire was filled by the study participants, and then the results were analyzed and expressed in percentage at the end of the study.

\section{RESULTS}

Comparing the knowledge, awareness and attitude about RUM of both the groups of pharmacists in Coimbatore was done. While comparing the knowledge about RUM in community pharmacists in and around Coimbatore, was found to be $59 \%$ and $49 \%$ respectively (Table 1 ).

Table 1: Knowledge, awareness and attitude towards rational use of medicines by community pharmacists in and around Coimbatore.

\begin{tabular}{|lllll|}
\hline $\begin{array}{l}\text { Questionnaire - } \\
\text { contents }\end{array}$ & Yes & No & Yes & No \\
\hline $\begin{array}{l}\text { Awareness about } \\
\text { RUM concepts }\end{array}$ & 59 & 41 & 49 & 51 \\
\hline $\begin{array}{l}\text { Demanding } \\
\text { prescription before } \\
\text { dispensing the drug }\end{array}$ & 65 & 35 & 80 & 20 \\
\hline $\begin{array}{l}\text { Issued medicines for } \\
\text { same / old } \\
\text { prescriptions }\end{array}$ & 72 & 28 & 81 & 19 \\
\hline $\begin{array}{l}\text { Alert to the public } \\
\text { about the ill effects of } \\
\text { drugs }\end{array}$ & 79 & 21 & 69 & 31 \\
\hline $\begin{array}{l}\text { Guiding patient about } \\
\text { the possible ADR }\end{array}$ & 79 & 21 & 69 & 31 \\
\hline $\begin{array}{l}\text { Guiding patients to } \\
\text { report about ADR (if } \\
\text { any) }\end{array}$ & 72 & 28 & 69 & 31 \\
\hline $\begin{array}{l}\text { Dispensed medicines } \\
\text { with appropriate } \\
\text { dosage and duration }\end{array}$ & 82 & 18 & 51 & 49 \\
\hline $\begin{array}{l}\text { Check expiry date of } \\
\text { the drug before } \\
\text { dispensing }\end{array}$ & 92 & 8 & 94 & 6 \\
\hline $\begin{array}{l}\text { Any observation with } \\
\text { repeated request to } \\
\text { issue medicine on } \\
\text { demand /dependence } \\
\text { to drugs }\end{array}$ & 49 & 51 & 71 & 29 \\
\hline $\begin{array}{l}\text { Observed any } \\
\text { injections related ADR } \\
\text { (injection abscess, } \\
\text { hepatitis etc) }\end{array}$ & 2 & 98 & 1 & 99 \\
\hline
\end{tabular}


Community pharmacists were dispensing medicines without prescription was $65 \%$ in Coimbatore and was $80 \%$ around Coimbatore. The reasons for dispensing medicines without prescription by both groups were compared and the major reason identified was patient's request (Figure 1). $6 \%$ of community pharmacists inside Coimbatore city are dispensing medicines without prescription because of emergency. Community pharmacists in and around Coimbatore were issuing drugs over the counter and the percentage was $38 \%$ and $41 \%$ respectively and $3 \%$ had other reasons for dispensing medicines without prescription.

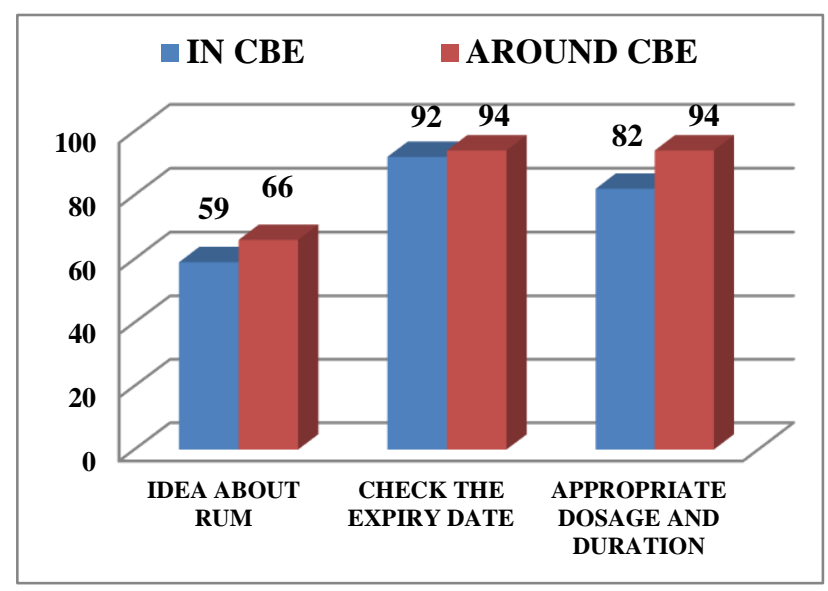

Figure 1: Knowledge about rational use of medicine in \%.

The next comparison between the community pharmacists were those issuing medicines for old prescriptions, which was $72 \%$ and $81 \%$ respectively. (Table 1 ) The number of times medicines issued for the old prescriptions was analysed (Figure 2). About 56\% and $74 \%$ of community pharmacists in both the groups are dispensing medicine for the old prescription more than once. Some community pharmacists in and around Coimbatore are issuing medicine for the old prescription only once around $11 \%$ and $1 \%$ respectively.

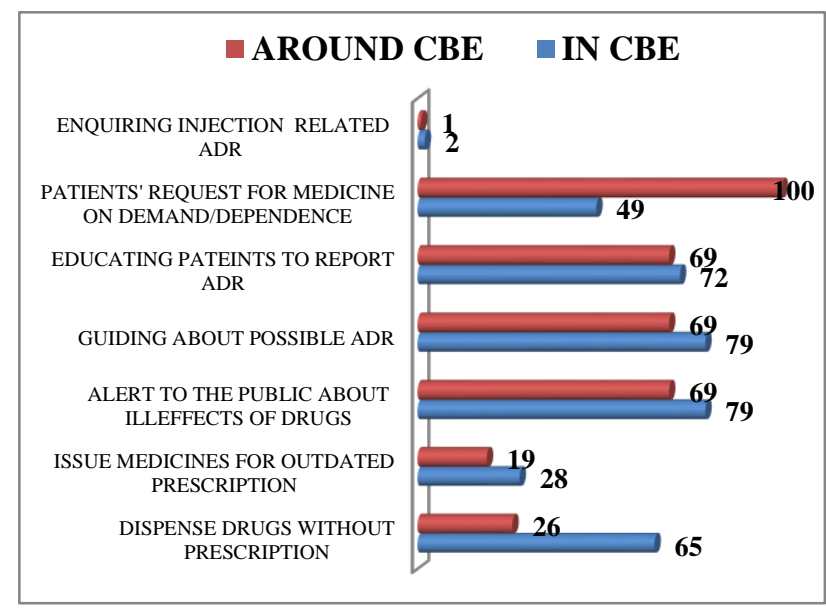

Figure 2 :Awareness and attitude about rational use of medicine in $\%$.
There was a comparison between the two groups whether these pharmacists were provided alert to the public about the ill effects of drugs. Community pharmacists in and around Coimbatore were all most equal in giving alert to the public about the ill effects of drugs (70\%-80\%) (Table 1) when compared to international study ${ }^{(4)}$ this study showed a good indicator.

Regarding the Pharmacovigilancereduction program, whether the community pharmacists in and around Coimbatore guided the patients to report the ADRs was found to be almost equal around $65 \%-75 \%$ (Table 1).

A RUM concept of dispensing medicine for appropriate dosage and duration were compared between the two groups of the community pharmacists in and around Coimbatore was found that $82 \%$ and $51 \%$ of community pharmacists in and around Coimbatore respectively were dispensing medicines in appropriate dosage and duration (Table 1).

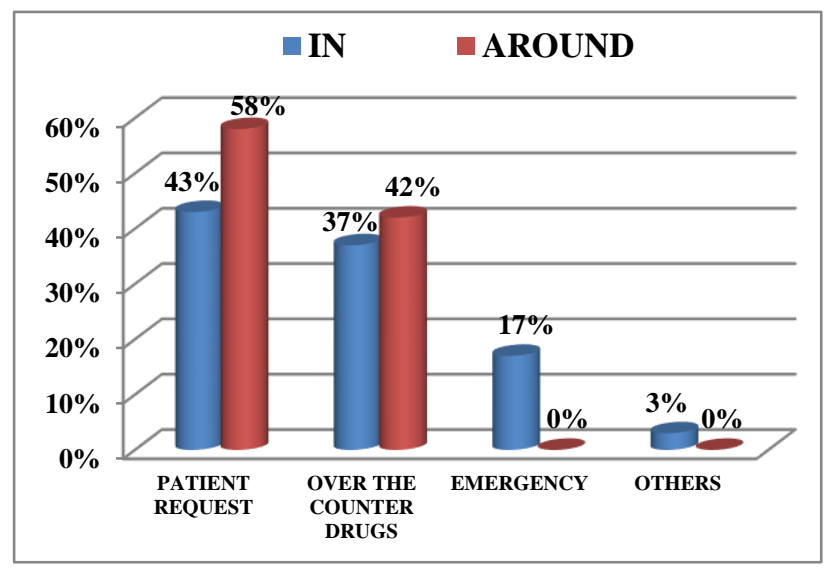

Figure 3: Reasons for issuing medicine without prescription in $\%$.

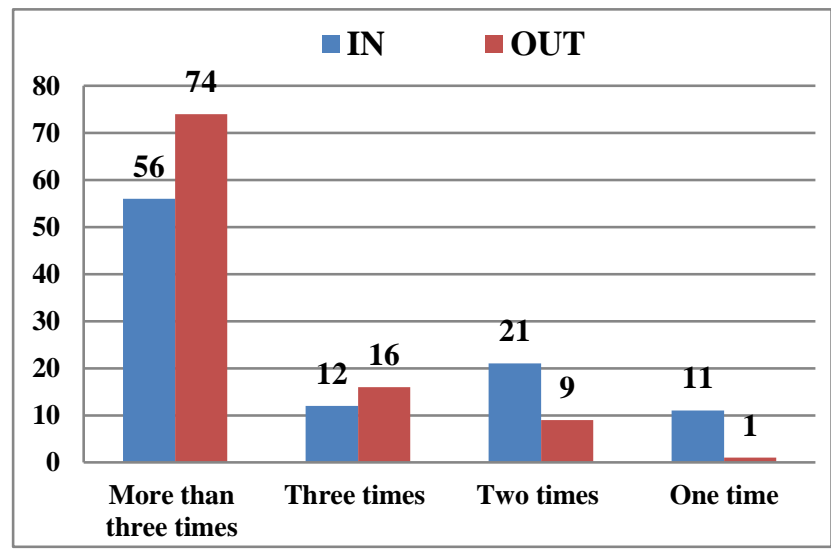

Figure 4: Frequency of issuing medicine for the same old/out dated prescription in \%.

92\%-94\% of in and around Coimbatore Community pharmacists were checking expiry date before dispensing the drugs (Table 1) compared to an international study 
which was $41 \% .^{4}$ This study could not observe any injection related ADR in both groups. Patients repeatedly requesting to issue medicine without any prescriptions were $49 \%$ and $71 \%$ respectively (Table 1 ). Medicines which were given repeatedly without prescription were pain killers and it was $45-50 \%$ in both the groups. Cough syrups were the second commonly issued medicine with repeated request by the patients which was around $35-45 \%$ in both the groups. The community pharmacists in Coimbatore were expressed that $12 \%$ of patients are repeatedly requesting to issue antibiotics, while community pharmacists around Coimbatore report that $11 \%$ of patients are repeatedly requesting to issue sedatives. The number of patients repeatedly requesting to issue sedatives in Coimbatore is only $2 \%$ (Figure 3 ).

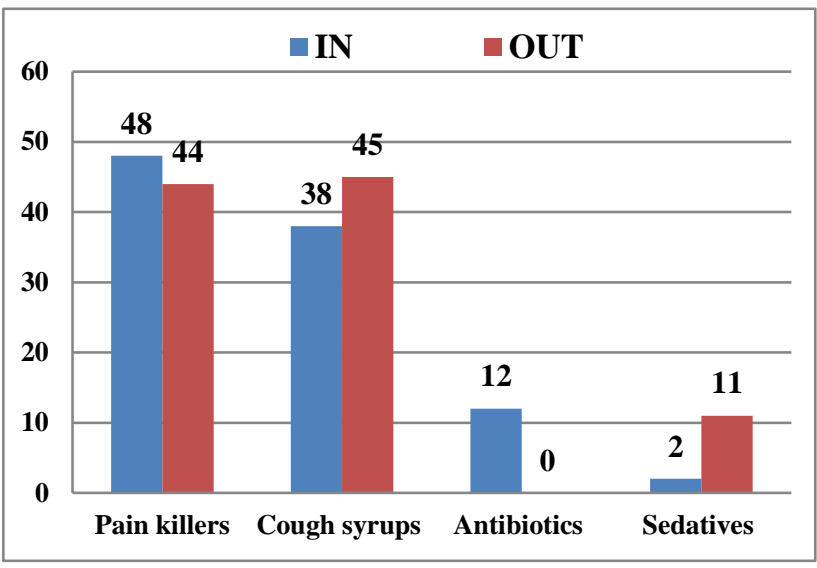

Figure 5: List of repeated use of drugs without prescription in $\%$.

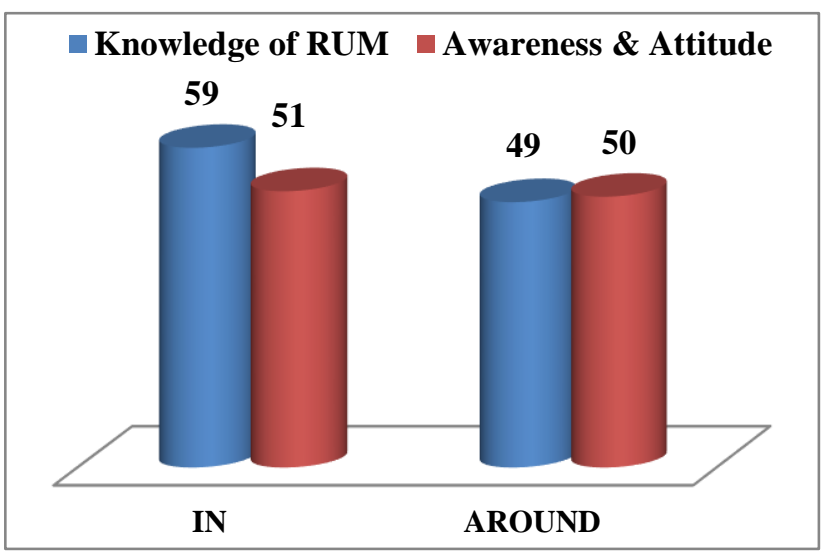

Figure 6 : Knowledge of RUM, awareness and attitude among the community pharmacist in and around coimbatore in $\%$.

\section{DISCUSSION}

This study was the first kind study India which tried to assess the knowledge, attitude and awareness of community pharmacists in and around Coimbatore (metro population city) towards rational use of medicine. Community pharmacies are the part of the healthcare system throughout the world. Community pharmacists act as a first-line treatment source for most of the population diversity in their distribution and setups make them an easily accessible. Community pharmacists are a quick source of advice, referral, dispensing medicines and information to the patient's. The way drugs are procured, stored and dispensed and the information given by the dispensers indicates the quality of their practice leading to rational or irrational use of medication.

This study found that only around 55\% of community pharmacists have the idea about RUM (Table 1). A similar study was done in another country found that community pharmacists lacked awareness and knowledge about RUM. ${ }^{5,6}$

While comparing the reasons for issuing drugs without prescription, in this study majority of the community pharmacists were issued the medicines at the patient's request and also, they issued medicines over the counter without prescription (Figure 3 ). In an international study it was expressed that no need for the prescription for chronic and CNS diseases and also they were dispensed medicines without prescription because patient asked for the drug by name. $^{6}$

This study found that community pharmacists dispensed medicines for old prescriptions. A similar finding was seen in another study, where medicines were issued for old prescriptions for months. ${ }^{7}$

In this study it was found that the number of community pharmacists provided alert to the public about the ill effects of drugs was $79 \%$ and $69 \%$ respectively in and around Coimbatore. There was a study expressing that only 40$50 \%$ community pharmacists provide alert the public about the ill effects of drugs.

In another study it was found that community pharmacists guiding patients to report ADR was deficient. ${ }^{4,9}$ But in this study, it was found that community pharmacists guiding patients for possible ADRs was 79\% - and 69\% and provided guidance to report ADR $72 \%$ and $69 \%$ respectively in and around Coimbatore.

It was found that, $82 \%$ and $51 \%$ of community pharmacists in and around Coimbatore was dispensing medicines in the appropriate dosage and duration. But a study done in another country had found that $97 \%$ of community pharmacists were dispensing antibiotics irrationally. ${ }^{6}$

In this study, it was confirmed that, almost all the community pharmacists check expiry date before dispensing the drugs and only $1.3 \%$ were enquired and observed ADRs related to injection.

This study also bring out that, the community pharmacists issued medicine without demanding prescriptions was $35 \%$ and $20 \%$ in and around Coimbatore compared to another international study which had expressed about the 
patients repeated request to issue medicine without any prescriptions. $^{10}$

Knowledge and attitude of the community pharmacists on drug safety and related aspects could greatly influence their dispensing behavior and thereby positively contribute to the patient safety. Majority of the community pharmacists had low acceptable knowledge on drug safety related aspects for specific drugs and a good number of them were not aware of certain practical aspects. ${ }^{11}$

In many places it was observed that, the practice of irrational drug use like self-medication, antibiotic prescribing, and sale of less-than-prescribed quantity of drugs specially antibiotics, and finally poor drug storage practices. Global research provides the evidence that it's possible to improve and regulate the practice of community pharmacists through a combination of interventions, education to achieve the goal of promoting RUM. Changing their knowledge and practices would be a slow, difficult and challenging procedure, but if the intervention once done it efficiently improves the skills even in the most resource-deprived settings.

Educational interventions with interactive training sessions if provided would be useful in improving prescribing practices of the community pharmacists like proper drug storage, record-keeping, reading doctor's prescription, medication counselling, discouraging sale of antibiotics without prescription, promoting quality dispensing of medicine etc may improve the practices in a possible way through appropriate and repeated interventions which are sustained. ${ }^{12}$ There is a compelling need for the development of a clear policy on promoting rational use of medicine involving all segments of health care system such as physicians, community pharmacists, drug companies and government agencies. This will ensure that rational use of medicines which will benefit the community can be achieved. ${ }^{12}$

There is a definite need for the development of a clear educational policy on promoting rational use of medicine involving all segments of health care system such as physicians, community pharmacists, drug companies and government agencies to ensure that rational use of medicines benefits in the community. ${ }^{12}$ Community Pharmacist require continues educational services like frequent update, scientific meeting, creating and providing good communication activities with physicians, training pharmacy staffs, adhering treatment principles, RUM practices, skill development opportunities, technical support, and pharmacy education may reduce the gap between health care system and community. ${ }^{13,14}$

\section{CONCLUSION}

The World Health Organization has recognized few factors like patient demands, drug advertising etc as limitations towards achieving rational use of medicine based on various research evidence. If an appropriate intervention applied in the needy area may be helpful to improve RUM practices in the community where the pharmacist's services are very important segment in the health care system of many countries.

Funding: No funding sources

Conflict of interest: None declared

Ethical approval: The study was approved by the Institutional Human Ethics Committee (14 /331)

\section{REFERENCES}

1. WHO. Promoting rational use of medicines: core components WHO Policy Perspectives on Medicines. September 2002.

2. Alabid AH, Ibrahim MI, Hassali MA. Antibiotics Dispensing for URTIs by Community Pharmacists (CPs) and General Medical Practitioners in Penang, Malaysia: A Comparative Study using Simulated Patients (SPs). J Clin Diagn Res. 2014;8(1):119-23.

3. Toklu HZ, Hussain A. The changing face of pharmacy practice and the need for a new model of pharmacy education. J Young Pharm. 2013 Jun;5(2):38-40.

4. Rasool BK, Fahmy SA, Abu-Gharbieh EF, Ali HS. Professional practices and perception towards rational use of medicines according to WHO methodology in United Arab Emirates. Pharm Pract. 2010 Jan;8(1):706.

5. Hussain A, Ibrahim MI, Baber ZU. Using the potentials of community pharmacies to promote rational drug use in Pakistan: an opportunity exists or lost? J Pak Med Assoc. 2012 Nov;62(11):1217-22.

6. Al-Mohamadi A, Badr A, Bin Mahfouz L, Samargandi D, Al Ahdal A. Dispensing Medications without prescription at Saudi community pharmacy: Extent and perception. Saudi Pharm J. 2013 Jan;21(1):13-8.

7. Kolhatkar A, Cheng L, Chan FK, Harrison M, Law MR. The impact of medication reviews by community pharmacists. J Am Pharm Assoc. 2016 SepOct;56(5):513-20.

8. Cohen MR, Smetzer JL, Westphal JE, Comden SC, Horn DM. Risk models to improve safety of dispensing high-alert medications in community pharmacies. J Am Pharm Assoc. 2012 SepOct;52(5):584-602.

9. Ting KN, Stratton-Powell DM, Anderson C. Community pharmacists' views on adverse drug reactions reporting in Malaysia: a pilot study. Pharm World Sci. 2010 Jun;32(3):339-42.

10. Tommasello AC. Substance abuse and pharmacy practice: what the community pharmacist needs to know about drug abuse and dependence. Harm Reduct J. 2004 Apr20;1(1):3.

11. Jose J, Jimmy B, Al-Ghailani AS, Al Majali MA. A cross sectional pilot study on assessing the knowledge, attitude and behavior of community pharmacists to adverse drug reaction related aspects in the Sultanate of Oman. Saudi Pharm J. 2014 Apr;22(2):163-9.

12. Hussain A, Ibrahim MI, Baber ZU. Using the potentials of community pharmacies to promote 
rational drug use in Pakistan: an opportunity exists or lost? J Pak Med Assoc. 2012 Nov; 62(11):1217-22.

13. Dosea AS, Brito GC, Santos LM, Marques TC, BalisaRocha B, Pimentel D, et al. Establishment, Implementation, and Consolidation of Clinical Pharmacy Services in Community Pharmacies: Perceptions of a Group of Pharmacists. Qualitative health research. 2017 Feb; 27(3):363-73.

14. Puspitasari HP, Aslani P, Krass I. Challenges in the management of chronic no communicable diseases by
Indonesian community pharmacists. Pharmacy Practice. 2015 Jul-Sep;13(3):578.

Cite this article as: Bhuvaneswari $\mathrm{K}$, Jeyalakshmi D, Umamaheswari A. Knowledge, awareness and attitude towards rational use of medicines by community pharmacists in and around Coimbatore, India. Int J Basic Clin Pharmacol 2017;6:2422-7. 